\title{
OS VERDADEIROS VERBOS MODAIS DA LÍNGUA INGLESA A PARTIR DE UMA PERSPECTIVA DIACRÔNICA: AS SIGNIFICAÇÕES ATRELADAS À SEMÂNTICA DE MUNDOS POSSÍVEIS
}

\author{
Mariane Garin Belando \\ Doutoranda em Linguística pela Universidade Federal de Santa Catarina (UFSC) \\ marianebelando@yahoo.com.br
}

\section{RESUMO}

Este artigo tem por objetivo considerar que as noções semânticas estabelecidas aos verdadeiros verbos modais da língua inglesa, observados como em um estágio final de gramaticalização, necessitam ser relacionadas e analisadas diacronicamente para uma melhor depreensão de suas funções. A hipótese é a de que a repetição de uso de determinados itens lexicais os tornou funcionais, até atingirem a leitura epistêmica, gerando mudança de escopo em relação às proposições. Mas, para isso, considera-se que a modalidade orientada para o agente se tornou crucial para que a gramaticalização destes verbos se instaurasse na língua. As considerações finais sugerem que tal processo evolutivo é capaz de demonstrar que estes verbos são, na verdade, polissêmicos, cujas significações estão vinculadas ao conceito de mundos possíveis, em referência às possibilidades dos fundos conversacionais.

Palavras-chave: verbos modais, diacronia semântica, semântica de mundos possíveis.

\section{ABSTRACT}

This paper intends to consider that the semantic notions established to the true verbal modal verbs in English, observed as a final stage of grammaticalization, need to be related and analyzed diachronically for a better understanding of their functions. The hypothesis is that the repetition of certain lexical items made them functional until they reached the epistemic reading, developing a change of scope in relation to the propositions. But for that, it is considered that the agent-oriented modality became crucial for the grammaticalization of these verbs has been established in the language. The final considerations suggest that such an evolutionary process is able to demonstrate that these verbs are indeed polysemic, whose meanings are linked to the concept of possible worlds, in reference to the possibilities of conversational backgrounds.

Keywords: modal verbs, diachronic semantics, possible world semantics. 


\section{Introdução}

Ao se pretender estudar os efeitos da modalidade nas línguas, torna-se necessário, antes de mais nada, delimitá-la. Muitas são as suas definições, como a de significar "a gramaticalização de atitudes e opiniões dos falantes" (OLIVEIRA, 2003, p. 245); a de se tratar de inferências ou conclusões essencialmente subjetivas e performativas realizadas por determinado falante e recorrentes no momento de fala (PALMER, 2001).

Porém, embora sejam acepções amplamente aceitas, Bybee (1985) questiona a impossibilidade de realizar uma caracterização sucinta de seu domínio, assim como da noção de sua parte que é expressa gramaticalmente. Para a autora, modalidade são formas gramaticais empregadas através das línguas e só faz sentido estudá-las se baseadas em suas funções relacionadas diacronicamente.

Para Bybee (2001), o uso repetitivo de itens lexicais de uma língua no decorrer de sua história seria o responsável pela redução de formas, como no inglês going to que deu origem a gonna, ou he is e I will, vertendo-se, respectivamente, em he's e I'll.

Seria, então, a repetição a responsável pela automatização dos movimentos articulatórios, além de emancipações, estas observadas nos processos de gramaticalização nos quais palavras perdem características categoriais, como verificados em verbos que se tornaram auxiliares e até mesmo afixos, sendo dissociados de seus significados lexicais e assumindo funções gramaticais e pragmáticas. E é dentro desse cenário que os verbos modais se desenvolveriam (BYBEE, 2001). 
Os verbos modais, ao serem formados a partir dos processos de gramaticalização, perderiam conteúdo lexical, dando margem para que morfemas funcionais fossem estabelecidos e atrelados a determinadas significações.

De acordo com Xavier (2008) sobre a língua inglesa, a morfologia verbal correspondente às flexões de futuro e de subjuntivo desaparecera, o que acentuou a necessidade de gramaticalização dos verbos considerados semimodais e, consequentemente, constitui-se a classe dos verdadeiros verbos modais a partir do século XVI.

Sobre os auxiliares semimodais, a título de esclarecimento e à distinção dos verdadeiros modais, eles carecem "da intermediação de um complementizador" (PIRES DE OLIVEIRA; SCARDUELLI, 2008), a exemplo de have to, além de poderem aparecer também como verbo principal em algumas sentenças, como o verbo need (STOWELL, 2004). São diferenças que correspondem a comportamentos sintático e semântico distintos (PIRES DE OLIVEIRA; SCARDUELLI, 2008), sendo que os verdadeiros modais estão em um estágio final de gramaticalização.

Assim, os verdadeiros modais da língua inglesa, objeto deste estudo, são aqueles que se ligam diretamente à proposição e que não possuem um estatuto sintático duplo. Trata-se de verbos que apresentam características muito particulares e homogêneas e, pelo fato de ter ocorrido um maior enfraquecimento da morfologia flexional dos verbos em inglês, se comparado à da língua portuguesa, refletiu-se na morfossintaxe dos elementos funcionais daquela língua (XAVIER, 2008).

Trata-se, portanto, de uma pesquisa de cunho bibliográfico que tem por objetivo ao aliar as características semânticas inerentes aos processos de mudança nas línguas às condições sintáticas destas e ao tentar materializar os usos apropriados também das 
categorias gramaticais -, a partir de um viés diacrônico, compreender como os modais verdadeiros da língua inglesa adentraram gramaticalmente à língua, classificados segundo critérios semânticos, também diacronicamente relacionados, com o intuito de chegar ao sentido idealizado pelo falante ao produzir enunciados voltados ao seu interlocutor.

E para que isto se torne possível, um tipo de modalidade deve ser compreendido, a saber, o da orientada para o agente (BYBEE; PERKINS; PAGLIUCA, 1994). Isto se justifica, pois por mais que esta modalidade seja observada como parte do conteúdo proposicional do enunciado - conteúdo subentendido no discurso, e que poderia, por consequência, não ser considerada uma modalidade propriamente dita em estudos estruturais -, seus significados modais são considerados, de acordo com Bybee, Perkins e Pagliuca (1994), as fontes diacrônicas da maioria dos sentidos estabelecidos para que o termo modalidade seja qualificado como tal nos estudos sincrônicos, capaz de evidenciar certos processos avançados de gramaticalização. E, desse modo, o presente artigo pretende questionar a relevância de tal modalidade.

Deste modo, tem-se, na primeira seção, para melhor situar o leitor, um breve resumo de quais são os verdadeiros verbos modais da língua inglesa contemporânea, salientando o inglês americano. Na segunda seção, aborda-se o que seria a modalidade orientada para o agente e como se deu sua evolução, exemplificando suas noções semânticas, até que pudessem estabelecer a possibilidade epistêmica, o que geraria uma mudança de escopo. Tal evolução de comportamento destes modais será relacionada à semântica de mundos possíveis (KRATZER, 1991, 2012; LEIBNIZ (2007 [1710]), observadas na terceira seção, no sentido de que os conceitos de verdade de uma proposição são determinados através do contexto de uso, contexto este capaz de ordenar os mundos e 
especificar suas leituras, reconhecendo como verdadeiros determinados fundos conversacionais.

\section{Os verdadeiros modais da língua inglesa}

De acordo com Xavier (2008) e Stowell (2004), os verdadeiros modais da língua inglesa não podem aparecer em formas não finitas, embora não se flexionem concordando com a terceira pessoa do singular; não necessitam do do-support, ou seja, em sentenças interrogativas, o modal mesmo é o auxiliar; sempre precedem a partícula not em sentenças negativas; possuem verbos infinitivos nus ${ }^{\mathrm{ii}}$ como complemento; e não apresentam informação inerente sobre tempo presente ou passado.

Outro fator é o de que estes verbos estão em distribuição complementar, na qual a presença de um exclui a presença de outro modal, sempre ocupando a mesma posição sintática. Tais restrições evidenciam o quão desenvolvido foi o processo de gramaticalização desses verbos na língua inglesa ao se comparar, por exemplo, aos da língua portuguesa, pelas possibilidades de flexão nestes e de ocorrerem conjuntamente em uma mesma sentença.

Há, na língua inglesa, dez verbos modais considerados verdadeiros, a saber: can, could, may, might, must, shall, should, will, would e ought, sendo este o único a admitir to complementar. (COATES, 1983; STOWELL, 2004).

Os verdadeiros modais se distinguem dos verbos lexicais também em relação à diferenciação temporal, pois, em um conjunto restrito de contextos sintáticos, alguns verdadeiros modais apresentam uma alternância de tempos presente/passado, como can/could, shall/should e will/would, respectivamente, observados no inglês americano 
coloquial contemporâneo, e may/might, em apenas alguns dialetos considerados conservadores (STOWELL, 2004). Ainda, de acordo com o autor, must e ought to não apresentam alternância morfológica de tempo, sendo que must e may, em muitas situações, são observados em sentenças no presente, enquanto ought e might parecem se comportar de forma ambígua nos contextos sintáticos nos quais os grupos com presente e passado delimitados se disporiam.

\section{A modalidade orientada para o agente e sua evolução}

Esta modalidade refere-se à existência de condições internas e externas influenciando sobre um determinado agente na execução da ação disposta no enunciado. Trata-se do uso de morfemas gramaticais com noções semânticas específicas nas quais está associado um significado-fonte, voltado ao agente (BYBEE; PERKINS; PAGLIUCA, 1994). Dentro destas noções, temos a de obrigação, que infere a existência do externo, de condições sociais que convençam um agente a realizar a ação que está sendo predicada, podendo ser uma obrigação forte, como em (1), ou fraca, como expressa em (2):

(1) All students must obtain the consent of the Dean of the faculty concerned before entering for examinations (COATES, 1983, p. 35).

(Todos os estudantes têm de obter o consentimento do reitor do departamento em questão antes de entrarem para os exames ${ }^{\mathrm{iii}}$.)

(2) They should tell only the truth.

(Eles devem dizer somente a verdade.) 
Outra noção semântica é a de necessidade, depreendendo a existência de condições físicas que possibilitem o agente a completar a ação, como em (3):

(3) "You must iv play this ten times over", Miss Jarrova would say, pointing with relentless fingers to a jumble of crotchets and quavers (COATES, 1983, p. 31).

(Você precisa tocar isso dez vezes mais, diria a senhorita Jarrova, apontando com dedos implacáveis para um amontoado de semínimas e colcheias.)

Há a noção de habilidade/capacidade, que reporta à existência de condições internas que permitam a execução da ação, como em (4):

(4) I can only type very slowly as I am quite a beginner (COATES, 1983, p. 92).

(Eu só posso digitar muito vagarosamente porque eu sou realmente um aprendiz.)

E a noção semântica de desejo, que diz respeito à existência de condições volitivas internas no agente com respeito à ação predicada.

(5) "Juan Ortiz called to them loudly in the Indian tongue, bidding them come forth if they would save their lives" (COATES, 1983, p. 212).

(Juan Ortiz gritou a todos na língua indígena, mandando seguirem em frente para que salvem eles suas vidas.)

Nesse exemplo, presencia-se o modal would em uma cláusula condicional, podendo ser parafraseada por if they wanted to save their lives (COATES, 1983, p. 212), evidenciando um uso pragmático arcaico para este modal, com sentido volitivo e substituinte polido de uma forma no imperativo, forma a qual foi utilizada na tradução da sentença (5), por ser considerada a mais adequada ao contexto. 
Quanto às noções semânticas acima estabelecidas, há relações diacrônicas que fundamentam a evolução de sentidos de tais modais. Como exemplo, necessidade evoluiu para desejo com a palavra want, a partir do século XVIII, palavra esta proveniente de um verbo nórdico antigo que significava to lack or miss (BYBEE; PERKINS; PAGLIUCA, 1994, p. 178). Sentidos semânticos mais específicos puderam ser generalizados ao longo do tempo, mas que, no entanto, eram todos voltados para as condições das quais o agente dispunha.

No inglês médio (por volta do século XI ao século XV), tanto as noções de desejo quanto de obrigação eram voltadas somente ao agente, o que implicavam o uso de will (medieval $w y l$ ), enquanto palavra originária para expressar desejo, e shall (medieval schal), primária para obrigação, apenas para exprimir as condições direcionadas à primeira pessoav

A possibilidade raiz, termo este utilizado para contextos de modalidade deôntica (COATES, 1983), representou uma generalização da habilidade, informando sobre condições mais gerais, como físicas, sociais e éticas, e não somente às internas, fazendo com que se perdesse seu caráter específico e se dirigisse, paulatinamente, às características externas que excederiam às condições inerentes ao agente. Dessa forma, o modal may (primitivo $m \square g$ ), que iniciara seu uso como capacidade interna ao agente, passou a ser utilizado para habilidades mais gerais já no inglês antigo, este com início no século V (BYBEE; PERKINS; PAGLIUCA, 1994), como podemos observar em (6):

(6) ThDr $m \square g$ nihta gehwDm nith-wundor seón (BYBEE; PERKINS; PAGLIUCA, 1994, p. 193).

'A wonder can be seen there every night.'

(Um milagre pode ser visto lá todas as noites.) 
Foi a partir da possibilidade raiz que tanto o may quanto o can passaram a ser utilizados para relatar permissão, na qual um agente está autorizado a fazer algo, visto que um sentido de possibilidade raiz mais geral incluiria, intuitivamente, a significação de permissão social. A forma utilizada para pedir ou conceder uma permissão nada mais seria do que uma instância da possibilidade raiz, pois um modal, ao expressar habilidade, não poderia evoluir diretamente para a noção permissiva sem antes ser capaz de expressar a possibilidade raiz.

Em vista disso, pode-se propor um esquema dos verbos modais da língua inglesa, de acordo com o processo evolutivo de suas significações voltadas ao agente, até alcançarem a possibilidade epistêmica, conforme a Figura 1.

Figura 1 - Processo evolutivo das características semânticas dos verbos modais

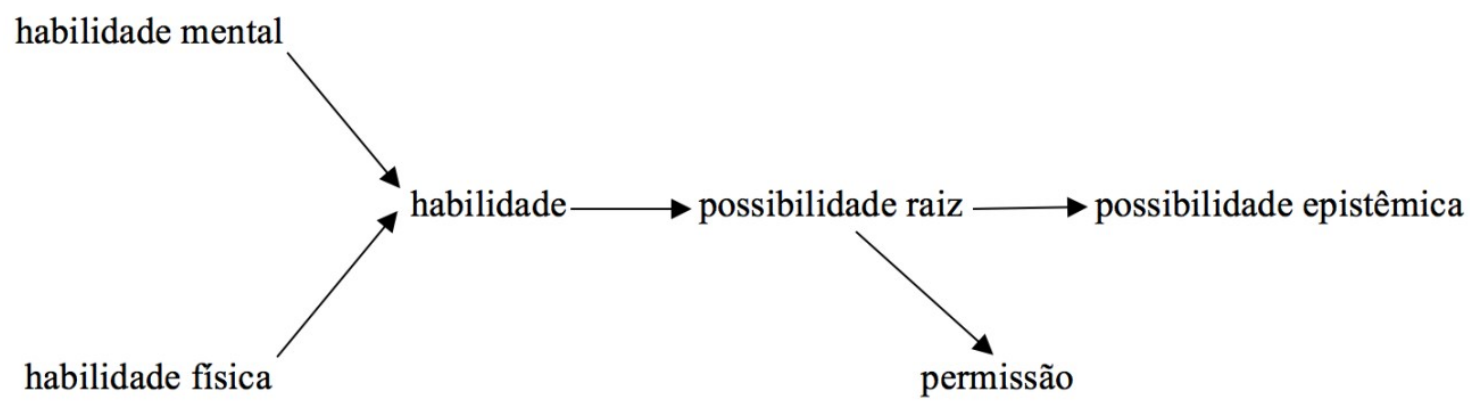

Fonte: BYBEE; PERKINS; PAGLIUCA (1994, p. 194-199, adaptado).

Textos do inglês medieval apresentavam enunciados com o modal may significando possibilidade raiz, mas com a possibilidade epistêmica implícita, introduzindo-os, assim, ao domínio da probabilidade, como se percebe em (7):

(7) 3e ar a sleper ynslyze, pat mon may slyde hider (BYBEE; PERKINS; PAGLIUCA, 1994, p. 198). 
'You are so unwary a sleeper that someone $c a n^{\text {vi }}$ sneak in here.'

(Você é um dorminhoco tão ingênuo que alguém pode roubar aqui.)

Em textos dessa época, a possibilidade epistêmica já pode ser inferida, o que evidenciaria uma mudança de escopo, afastando-se do agente, indo para além desta parte do conteúdo e se tornando externo, externo ao conteúdo proposicional, ou melhor, o verbo modal epistêmico teria toda a proposição em seu escopo.

Tais características parecem evidenciar que a maioria das mudanças semânticas em relação à gramaticalização foram graduais, no que diz respeito também à transição de escopo, demonstrando que os enunciados gradualmente se prenderiam ao momento de fala, preconizando que a mudança de habilidade para possibilidade raiz foi precondição para o desenvolvimento da possibilidade epistêmica.

Isto posto, a próxima seção procura demonstrar como esse processo evolutivo dos verbos modais pode estar relacionado ao conceito de mundos possíveis.

\section{O conceito de mundos possíveis}

O conceito de mundos possíveis teve sua origem na filosofia, sendo atribuído a Leibniz (2007 [1710]), como o princípio de uma infinitude de mundos possíveis, onde o bem e o mal existiriam, mas havendo a região das verdades eternas, realizada por Deus, na qual todas as condições, todas as hipóteses que se diferem nos mundos, todos os acontecimentos futuros, deveriam ali ser compreendidos. 
Essa condição de como as coisas são ou poderiam ser, em um mundo ideal, auxilia a semântica ao permitir que relações sejam delineadas, para que necessidades e possibilidades sejam quantificadas e depois qualificadas.

E isso ajudaria, no caso, na análise da modalidade, pois esta seria, portanto, uma quantificação de mundo possíveis, visto que, se uma proposição é necessária, significa dizer que ela é verdadeira em todos os mundos possíveis, porém, ao dizer que dada proposição é possível, indica que ela é verdadeira em determinados mundos possíveis. Deste modo, ao se falar sobre o que é necessário ou possível, não se faz referência apenas sobre a maneira como o mundo realmente é, mas, sim, à totalidade dos mundos possíveis (LOUX, 2006).

Para Kratzer $(1991,2012)$, os modais costumam ser pensados como ambíguos, porém, para a autora, eles se diversificariam a partir de variáveis distintas condicionadas pelo contexto, isto é, o contexto especificaria a leitura de determinado modal, implicando que a modalidade deve ser observada, portanto, em termos de modalidade relativa. Tais expressões podem ser caracterizadas através de dois eixos, sendo (1) a força modal, e (2) outro que especifique os fundos conversacionais admissíveis pelo contexto.

A força modal se refere à força de quantificação, a respeito da leitura de possibilidade e de necessidade dada no item lexical. Assim, as forças dos modais são determinadas lexicalmente, valendo-se de critérios de mundos, pois, como há línguas que possuem um modal para exprimir possibilidade e outro para necessidade, há outras línguas que possuem apenas modais existenciais ou modais com forças graduais em que a possibilidade possa ser comparada: se se trata da melhor possibilidade, de uma boa possibilidade, se é pequena a possibilidade de algo ocorrer, e se seriam mais ou menos desejáveis, já que, quando se fala em modais, fala-se de possibilidades (KRATZER, 2012). 
Quanto ao segundo eixo, este diz respeito à qualificação das distintas modalidades de acordo com o contexto. Por exemplo, se na sentença João deve ser um bom motorista, tem-se uma leitura deôntica, concernente ao julgamento avaliativo ou epistêmico, tal proposição e, por consequência, sua significação, são consubstanciadas pelo contexto de fala, pelo tempo do evento de fala, variando de acordo com os fundos conversacionais.

Seguindo Kratzer (2012), tais fundos conversacionais comportam duas categorias, a primeira relativa à base modal, e a segunda à fonte de ordenação. A base modal seria um dos fundamentos das distintas interpretações modais, incumbida de estabelecer um conjunto de proposições consistentes, proposições estas identificadas como um conjunto de mundos possíveis nos quais tais proposições possuam valor de verdade. Assim, quando diante de uma base modal epistêmica, tem-se um conjunto de proposições conhecido em determinado(s) mundo(s), ou melhor, consegue-se mapear os mundos epistemicamente acessíveis em que as proposições com este modal são verdadeiras.

Quanto à fonte de ordenação, esta é a responsável por determinar uma ordem aos mundos que integram certa base modal, a encarregada de dispor um domínio preliminar conforme um padrão ideal. Diante de uma fonte de ordenação deôntica, como exemplo, deve-se estabelecer uma ordem aos mundos de modo que estes se aproximem do ideal, do "melhor dos mundos", consoante a determinadas regras.

E é esta segunda categoria de fundo conversacional, a fonte de ordenação, que evidencia como a construção de mundos possíveis vai ao encontro das características dos modais observadas diacronicamente, pois, como haveria para cada mundo um conjunto de mundos acessíveis, isto apreenderia as gradações semânticas que perpassam os modais através de seus usos. Tem-se em cena os valores polissêmicos dos modais, 
dependentes do contexto, demonstrando que pressupostos homonímicos não se sustentam quando nas observações diacrônicas.

Dessa maneira, não há como postular que cada ocorrência de may, por exemplo, que fora utilizado mais primitivamente como capacidade interna ao agente, perpassado para habilidades mais gerais até chegar à possibilidade raiz, seja considerada como diferente de outra, a ponto de tais ocorrências serem concebidas como entradas distintas, crendo que itens lexicais foram se gramaticalizando diante de seus usos e originariam, cada, ideias de modalidade diversificadas, existindo $\operatorname{may}_{1}, m y_{2}, m y_{3}$ etc.

\section{Considerações finais}

A partir do exposto sobre o processo evolutivo dos verdadeiros modais do inglês, observado como pela repetição de uso, inferiu-se que a modalidade raiz (deôntica), como decorrência das distintas interpretações sobre habilidade, pôde ser subdividida, em quando orientada para o agente e em quando orientada para o falante.

Quanto à modalidade orientada para o agente, questionada na Introdução, o presente artigo salienta a sua relevância ao indicar que a sua aplicabilidade pode ser considerada a preconizadora do uso de modais na língua.

Sobre a modalidade orientada para o falante, esta não atribui a existência de condições sobre um agente, mas autoriza que determinado falante imponha tais condições, evidenciando um grau de engajamento ao precisar seu próprio enunciado em relação ao interlocutor, de acordo com as crenças que aquele supõe ou acredita que serão aceitas por este e, por conseguinte, dando margem para que atos de fala manipulativos pudessem ser gerados. 
A modalidade epistêmica veio a se solidificar, gradualmente, pelo fato de haver, já em textos do inglês antigo, evidências de que o falante se comprometeu com a verdade de seu enunciado, ocasionando uma mudança de escopo quanto ao conteúdo proposicional.

Por fim, aliando a diacronia aos estudos sincrônicos, entendeu-se que, com base no processo evolutivo dos significados modais, não é plausível considerar os modais como ambíguos. O mais adequado, como apontado por Kratzer (1991, 2012), é considerar sua multifuncionalidade, apreender seu caráter polissêmico, e perceber que há uma essência comum a todas as ocorrências de um certo modal, permanecendo invariável nos diversos mundos em que este é observado e, quem sabe possa, de acordo com o ideal de Leibniz (2007 [1710]), ocorrer tão verdadeiramente quanto é capaz de ser.

\section{Referências}

BYBEE, Joan. Phonology and language use. Cambridge: Cambridge University Press, 2001. Morphology: a study of the relation between meaning and form. Amsterdam/Philadelphia: John Benjamins Publishing Company, 1985.

BYBEE, Joan; PERKINS, Revere; PAGLIUCA, William. The evolution of grammar: tense, aspect, and modality in the languages of the world. Chicago: The University of Chicago Press, 1994.

COATES, Jennifer. The semantics of the modal auxiliares. London: Croom Helm, 1983.

KRATZER, Angelika. Modals and conditionals. New York: Oxford University Press, 2012. Modality. In: VON STECHOW, Arnim; WUNDERLICH, Dieter (eds.). Semantik Semantics: ein internationales Handbuch zeitgenössischen Forschung. Berlin: de Gruyter, 1991. p. 639-650. 
LEIBNIZ, Gottfried. Theodicy: essays on the goodness of God, the freedom of man and the origin of evil. Charleston: BiblioBazaar, 2007 (1710).

LOUX, Michael. Metaphysics: a contemporary introduction. 3. ed. New York: Routledge, 2006.

OLIVEIRA, Fátima. Modalidade e modo. In: MATEUS, Maria Helena et al (orgs.). Gramática da Língua Portuguesa. 5. ed. Lisboa: Editorial Caminho, 2003. p. 243-272.

PALMER, Frank. Mood and modality. 2. ed. Cambridge: Cambridge University Press, 2001.

PIRES DE OLIVEIRA, Roberta; SCARDUELLI, Jaqueline. Explicando as diferenças semânticas entre ter que e dever: uma proposta em semântica de mundos possíveis. Revista Alfa. São Paulo: Universidade Estadual Paulista, v. 52, n. 1, 2008. p. 215-234.

STOWELL, Tim. Tense and modals. In: GUÉRON, Jacqueline; LECARME, Alexander (eds.). The Syntax of time. Cambridge: The MIT Press, 2004. p. 621-636.

XAVIER, Maria Francisca. O percurso diacrónico dos modais e semimodais em português e em inglês e as suas gramáticas. In: LIMA-HERNANDES, Maria Célia et al. A língua portuguesa no mundo (I SIMELP). São Paulo: Universidade de São Paulo, 2008.

\section{Recebido em 15 de setembro de 2018.}

\section{Aceite em 4 de janeiro de 2019.}

\footnotetext{
' O presente trabalho foi realizado com apoio da Coordenação de Aperfeiçoamento de Pessoal de Nível Superior - Brasil (CAPES) - Código de Financiamento 001.

ii Bare infinitives, contrapondo-se ao to-infinitives ou full infinitives (infinitivos completos).

iii Todas as traduções são de responsabilidade da autora do presente artigo.

iv Quanto ao modal must, Coates (1983, p. 33) salienta a dificuldade de interpretação deste modal devido ao grau de envolvimento do falante no enunciado, ou seja, há sentenças que podem ser parafraseadas como "é necessário que...", além de "eu ordeno que você faça isso", o que mostra não haver uma linha divisória clara entre os casos que são subjetivos e os que não o são.

"No inglês moderno, o modal shall se manteve voltado à primeira pessoa do discurso, no singular ou pluralizada, mas voltado à ação futura e mais utilizado em interrogativas, com caráter mais formal.

vi Nesta tradução do inglês medieval, os autores preferiram a utilização do modal can porque transmitiria melhor uma leitura de raiz, argumentando que se trataria, portanto, de uma sentença ambígua.
} 